\title{
BILATERAL BREAST RECONSTRUCTION SURGERY: ECONOMIC PERSPECTIVES AND IMPLICATIONS ON THE QUALITY OF LIFE OF PATIENTS SUBMITTED TO UNILATERAL BREAST CANCER MASTECTOMY
}

Júlia J. Caetano¹, Guilherme A. Sampaio¹, Natália S. D. Mendonça¹, Laine R. Martins', Murilo H. C. Silva ${ }^{1}$ Faculdade de Medicina, Universidade Federal de Goiás - Goiânia (GO), Brazil.

Objective: Women with breast cancer (BC) can undergo breast reconstruction after mastectomy by the Unified Health System (SUS, acronym in Portuguese). New proposals intend to guarantee the right to perform mamoplasty of the autologous tissue seeking the symmetry of the breasts. The present work intends to discuss the consequences of this project in the economic scope for SUS and the quality of life for patients. Methodology: Data from the SUS Hospital Information System were used. Publications were searched on PubMed and BIREME platforms, using the descriptors bilateral breast reconstruction and breast cancer. Results: In a study carried out between 2002 and 2011 in a private clinic, the percentage of bilateral surgeries was $30 \%$ up to October 2007 and, from that period, passed to 84\%. In the SUS, 8,884 reconstructive mammoplasties after mastectomy with prosthesis implantation were performed between 2014 and 2018, totaling an expense of 8,047,860.04 reais and 33 bilateral reconstructive mammoplasties with prosthesis implantation, totaling 59,553.56 reais. The last procedure was not performed on women undergoing mastectomy to remove malignant tumor, and aims to only design expenditures if they could, in the future, be performed in the SUS in patients with BC. The cost of bilateral breast reconstruction is higher, but knowing that the diagnosis of $\mathrm{BC}$ represents a negative psychological impact, bilateral breast reconstruction is an option to reduce the damage to the self-esteem and sexual life produced by mastectomy, since the woman will have greater symmetry between the breast and better aesthetic perception of these, especially without clothes. Conclusion: Despite higher expenses, bilateral breast reconstruction in CM, including autologous tissue, is characterized as a necessary procedure to be performed in the SUS, since the patient's physical and psychic health should be prioritized, so that future complications in the mental and sexual dimensions are avoided. 